Published in final edited form as:

Org Lett. 2018 April 20; 20(8): 2216-2219. doi:10.1021/acs.orglett.8b00544.

\title{
Tin-Free Access to the ABC Core of the Calyciphylline A Alkaloids and Unexpected Formation of a D-Ring-Contracted Tetracyclic Core
}

\author{
Alberto M. Lopez ${ }^{\dagger}$, Ahmad A. Ibrahim ${ }^{\dagger}$, Gregory J. Rosenhauer, Hansamali S. Sirinimal, and \\ Jennifer L. Stockdill ${ }^{*}$ \\ Department of Chemistry, Wayne State University, 5101 Cass Avenue, Detroit, Michigan 48202, \\ United States
}

\begin{abstract}
A tin-free strategy for the successful cyclization of a variety of internal alkyne-containing $N$ chloroamine precursors to the $\mathrm{ABC}$ core via cyclization of a neutral aminyl radical is established. Deuterium labeling experiments confirm that the solvent is the primary source of the final $\mathrm{H}$ atom in the cyclization cascade. These conditions enabled a streamlined route to a $\beta$-ketoester intermediate poised for intramolecular Knoevenagel condensation to construct the sevenmembered D-ring of calyciphylline A alkaloids. However, exposure to $\mathrm{CsF}$ in $t-\mathrm{BuOH}$ at elevated temperatures led to an unexpected decarboxylation to form a D-ring-contracted tetracyclic core.
\end{abstract}

\section{Graphical abstract}

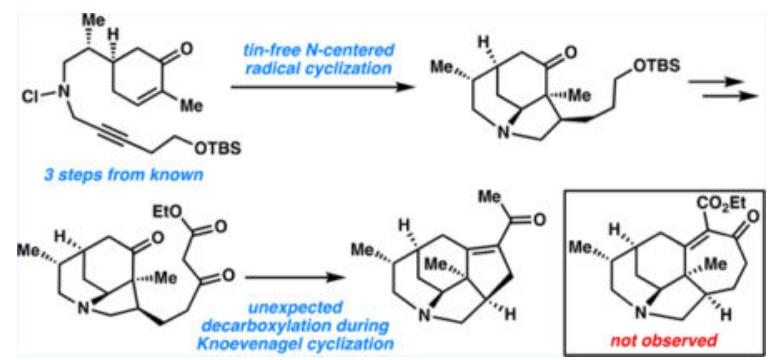

The Daphniphyllum alkaloids are a structurally complex family of polycyclic natural products isolated from deciduous shrubs and trees in Japan and Southeast Asia. ${ }^{1}$ Relative to the large number of isolates in this family, very few of these alkaloids have been investigated for biological activity. Of those that have reported activity, compelling functions, such as

*Corresponding Author: stockdill@ wayne.edu.

$\dagger$ A.M.L. and A.A.I. contributed equally.

Supporting Information

The Supporting Information is available free of charge on the ACS Publications website at DOI: 10.1021/acs.orglett.8b00544.

Experimental procedures and spectral data (PDF)

ORCID

Jennifer L. Stockdill: 0000-0003-4238-6530

Notes

The authors declare no competing financial interest. 
neurotrophic, antibacterial, and antitumor activities, have been reported. ${ }^{1,2}$ This combination of bioactivity and structural complexity has piqued the interest of the synthetic community, with dozens of reports of interesting strategies for the assembly of core motifs ${ }^{3}$ and several completed syntheses. ${ }^{4}$ Our efforts in this area were initially focused on the assembly of the $\mathrm{ABC}$ core of the calyciphylline A subfamily via tandem cyclization of an aminyl radical cascade mediated by a tributylstannyl radical. ${ }^{5}$ Here, we report the development of tin-free conditions for the construction of the $\mathrm{ABC}$ core that harness the $\mathrm{H}$ atom donating potential of THF in combination with a weak terminal $\mathrm{H}$ atom donor. Additionally, we describe efforts to assemble the D-ring of daphniyunnine $\mathrm{C}^{6}$ via a Knoevenagel condensation.

At the outset of our work, we envisioned disconnection of daphniyunnine $\mathrm{C}$ (1, also called longeracinphyllin A) to enedione $\mathbf{2}$ (Scheme 1). We hypothesized that the E- and F-rings could be assembled in one reaction vessel via phosphine-mediated [3+2]-cycloaddition with allene $3,{ }^{7}$ followed by addition of a catalytic acid to induce an in situ aldol condensation. Subsequent hydrogenation of the electron-rich olefin would then complete the synthesis. We envisioned that this cycloaddition approach would facilitate construction of the challenging vicinal all-carbon quaternary centers because the D-ring olefin in $\mathbf{2}$ is conjugated to the A-ring carbonyl. Thus, the first bond to be constructed would be remote from the quaternary center, rendering the construction of the new quaternary center an intramolecular event. This rationale was recently validated by $\mathrm{Li}$ and co-workers, ${ }^{8}$ who employed 1,1'-bis(diphenyl-phosphino)ferrocene and either an allenoate ester or allene $\mathbf{3}$ in cycloadditions toward daphniyunnine $\mathrm{C}^{4 \mathrm{~d}}$ and daphenylline, respectively. ${ }^{4 \mathrm{~b}}$ We envisioned assembly of the seven-membered ring from a ketone or $\beta$-ketoester (4) via aldol or Knoevenagel condensation ${ }^{9}$ of the corresponding enolates. The tricyclic core would be assembled via tandem cyclization of a neutral dialkyl aminyl radical derived from $\mathrm{N}$ chloroamine $\mathbf{5}$. Internal alkyne 5 would be assembled from lactol $\mathbf{6}^{5}$ and alkynyl azide 7 . Several possible $\mathrm{R}^{\prime}$ groups were envisioned, including masked ketone derivatives $\mathbf{7 a}-\mathbf{b}$ and protected alcohol 7c.

We previously reported the synthesis of the tricyclic core derived from the methallyl derivative $7 \mathbf{a},{ }^{5 \mathrm{~b}}$ but we were unable to advance the cyclization product (see $\mathbf{1 6}$, Scheme $5 \mathrm{~A}$ ). Thus, we focused on assembly of the cyclization precursor derived from alkyne $\mathbf{7 b}$ as described in Scheme 2. ${ }^{10,11}$ Generation of the lithium acetylide of alkyne $\mathbf{8}$ was followed by addition of paraformaldehyde to afford primary alcohol 8 in $67 \%$ yield. Due to challenges encountered with traditional reductive amination conditions, we imagined an alternative approach wherein an aza-Wittig reaction would be followed by reduction to the secondary amine. Thus, propargyl alcohol derivative 9 was mesylated, and then sodium azide was added to the reaction mixture to afford propargylic azide $\mathbf{7 b}$. This single-flask reaction was more efficient than a two-step process involving mesylation in dichloromethane followed by $\mathrm{NaN}_{3}$ displacement in DMF. A mixture of crude azide $\mathbf{7 b}$ and lactol ent-6 was treated with triphenylphosphine, and then an in situ reduction with lithium aluminum hydride provided the targeted amine (10) in 85\% yield. This amine could be chlorinated and the allylic alcohol oxidized in another single-flask procedure to afford the cyclization precursor ent-5b in $90 \%$ yield. By careful control of the reaction conditions, conversion of alcohol 9 to ent-5b, which 
would traditionally require six steps, was completed in three steps with an overall yield of $60 \%$.

With an efficient synthesis of chloroamine ent-5b in hand, we turned our attention to the key tandem cyclization to form the ABC core. Application of our previously optimized conditions ${ }^{5}$ led to highly variable results, with yields of $\mathbf{1 1}$ ranging from $0 \%$ to $48 \%$ yield, with the latter only achieved in one reaction (Scheme 3). Previous deuterium labeling studies established that $\mathrm{H}$ atom donation by the solvent was critical to achieving good cyclization yields. ${ }^{5 b}$ Thus, we screened other solvents capable of donating $\mathrm{H}$ atoms, including solvents with weaker and stronger $\mathrm{C}-\mathrm{H}$ bonds. In all cases, some of the desired product was observed, but the reaction performed in a sealed vessel at $100{ }^{\circ} \mathrm{C}$ in THF formed the fewest side products. ${ }^{12}$

We next turned our attention to the $\mathrm{H}$ atom donor. Tributyltin hydride has been a privileged participant in reductive radical chain processes because of its relatively weak $\mathrm{Sn}-\mathrm{H}$ bond (78 $\mathrm{kcal} / \mathrm{mol})$ coupled with the higher strength of the $\mathrm{Sn}-\mathrm{Cl}$ bond $(97 \mathrm{kcal} / \mathrm{mol}){ }^{13,14}$ Indeed, to the best of our knowledge, all previously reported thermal cyclizations of dialkyl aminyl radicals $\left(\mathrm{R}_{2} \mathrm{~N} \cdot\right)$ initiated at $\mathrm{N}-\mathrm{Cl}$ bonds have employed $\mathrm{Bu}_{3} \mathrm{SnH} .{ }^{15,16}$ In our reactions, the most frequently isolated byproduct is the uncyclized reduction product $\left(\mathrm{R}_{2} \mathrm{NH}\right)$. Thus, we envisioned that we could simultaneously avoid use of the toxic $\mathrm{Bu}_{3} \mathrm{SnH}$ and minimize $\mathrm{N}-\mathrm{H}$ bond formation ( $88 \mathrm{kcal} / \mathrm{mol}, \mathrm{H}$ atom abstraction by 12) by employing a weaker $\mathrm{H}$ atom donor (Scheme 4). Meanwhile, the $\mathrm{H}$ atom donor would need to form the final vinylic $\mathrm{C}-\mathrm{H}$ bond (105 kcal/mol, trapping of 14) with relative ease. Thus, we envisioned that an $\mathrm{H}$ atom donor with an $\mathrm{X}-\mathrm{H}$ bond between 88 and $\sim 100 \mathrm{kcal} / \mathrm{mol}$ would provide optimal reactivity. Notably, the BDE for THF falls into this range. Inspection of the reported bond dissociation energies (BDEs) ${ }^{14}$ for several $\mathrm{H}$ atom donors revealed that trialkylsilanes possessed bonds to hydrogen in this range $\left(\mathrm{Me}_{3} \mathrm{Si}-\mathrm{H}=95 \mathrm{kcal} / \mathrm{mol}, \mathrm{Et}_{3} \mathrm{SiH}=96 \mathrm{kcal} / \mathrm{mol},(t-\mathrm{Bu})_{3} \mathrm{SiH}=86.6\right.$ $\mathrm{kcal} / \mathrm{mol})$. Finally, a silane donor would also form a strong $\mathrm{Si}-\mathrm{Cl}$ bond $(113 \mathrm{kcal} / \mathrm{mol}$ for $\mathrm{TMSCl}$ ), minimizing the formation of $\mathrm{Cl}$ atom transfer products.

A brief optimization was conducted, leading to the optimal conditions: 2 equiv of TIPS-H, 0.2 equiv of AIBN, and $0.009 \mathrm{M}$ THF added all at once, followed by heating to $100{ }^{\circ} \mathrm{C}$ in a sealed tube. Importantly, these weak $\mathrm{H}$ atom donor conditions obviated the need for a slow addition of AIBN and the donor. At $66^{\circ} \mathrm{C}$ in THF or at $100{ }^{\circ} \mathrm{C}$ in benzene, no cyclization product was observed, but reduction products were detected. Use of TIPS-H in toluene at $100{ }^{\circ} \mathrm{C}$ led to low conversions $(<15 \%)$. These studies were complicated by the tendency of the product tricycle to react with $\mathrm{CH}_{2} \mathrm{Cl}_{2}$ during flash chromatography. ${ }^{17,18}$ Use of EtOAc/ hexanes on alumina led to a $68 \%$ yield of tricycle 11 on $49-\mathrm{mg}$ scale. Unfortunately, on larger scale, the yield dropped, and it proved difficult to advance significant amounts of material. ${ }^{19}$ We hypothesize that $1,5-\mathrm{H}$ atom transfer $(\mathrm{HAT})^{20}$ from a ketal $\mathrm{C}-\mathrm{H}$ to the vinylic radical $^{21}$ may be followed by nonspecific decomposition in this substrate.

Previously, we achieved consistent cyclization (58\% yield) with methallyl substrate $\boldsymbol{e n t}$-5a using $\mathrm{AIBN}, \mathrm{Bu}_{3} \mathrm{SnH}$ in toluene at reflux. ${ }^{5 \mathrm{~b}}$ For comparison, we treated $\boldsymbol{e n t}$-5a with various silanes in THF at $100{ }^{\circ} \mathrm{C}$ to good effect (Scheme 5A). Given the similar yields observed for these silanes, whose BDEs range from $\sim 86$ to $\sim 95 \mathrm{kcal} / \mathrm{mol},{ }^{14}$ we hypothesized that the 
solvent serves as the primary, if not exclusive, $\mathrm{H}$ atom donor to form the vinylic $\mathrm{C}-\mathrm{H}$ bond in these reactions and that the silane is a secondary donor of either a $\mathrm{H}$ atom or hydride. This hypothesis is further supported by $>99 \%$ incorporation of D during the cyclization of terminal alkyne substrate $\mathbf{1 7 ^ { 5 }}$ in the presence of $\mathrm{d}_{8}$-THF (Scheme 5B).

At this point, we directed our attention to the synthesis of cyclization precursor $\mathbf{4 b}$, derived from known alkynyl azide $\mathbf{7} \mathbf{c}^{22}$ bearing a TBS ether, which was expected to improve the solubility of our highly polar intermediates (Scheme 6). Assembly of $N$-chloroamine $\mathbf{4 b}$ began with an aza-Wittig reaction of lactol $\boldsymbol{e n t - 6}$ with azide 7c, followed by in situ reduction of the resulting imine with lithium aluminum hydride to form amine 19 in $84 \%$ yield.

Chlorination with NCS at $-78{ }^{\circ} \mathrm{C}$, followed by warming to $0{ }^{\circ} \mathrm{C}$ and addition of Dess-Martin periodinane under buffered conditions, afforded $N$-chloro enone ent-5c. Cyclization of $N$ chloroamine ent-5c under the optimized conditions led to the desired tricycle as well as some chlorine atom transfer product. ${ }^{11}$ Hydrogenation of both cyclization products with Adams' catalyst (20 mol \%) afforded tricycle 20 in $73 \%$ combined isolated yield over two steps.

The $\beta$-ketoester for the Knoevenagel strategy was prepared from tricycle $\mathbf{2 0}$ via a three-step procedure that is completed without purification of the intermediates (Scheme 7). ${ }^{23}$ Desilylation was executed by treatment with concentrated aqueous $\mathrm{HCl}$ in diethyl ether. The resulting primary alcohol was treated with 1 equiv of TFA to protonate the tertiary amine in situ, and then the alcohol was oxidized with DMP. Roskamp coupling ${ }^{24}$ was effected upon treatment with tin(II) chloride and ethyl diazoacetate, affording $\boldsymbol{e n t} \mathbf{- 4 b}$ in $54 \%$ yield over the three steps.

At this point, we were poised for cyclization of the D-ring via a Knoevenagel cyclization approach. Several bases were evaluated. Amine bases, including DBU, TEA, pyrrolidine, and piperidine, led to no reaction or trace conversion to enamines. Fluoride bases have proven to be effective mediators of Knoevenagel condensation in a variety of reports. ${ }^{25} \mathrm{We}$ selected CsF for its favorable solubility. Because of the neopentyl nature of the A-ring ketone, we chose an alcohol with a higher boiling point as solvent. Thus, $\beta$-ketoester $\boldsymbol{e n t - 2 3 \text { , }}$ in the presence of $\mathrm{CsF}$ in $t$-BuOH, was heated to $100{ }^{\circ} \mathrm{C}$ for $17 \mathrm{~h}$ (Scheme 8). ${ }^{12}$ No desired products were isolated, despite the complete consumption of the starting material (ent-20). Rather, D-ring-contracted methyl ketone $\mathbf{3 0}$ and pendant methyl ketone $\mathbf{3 1}$ were the only isolable products (11\% yield each). We hypothesize that either ester hydrolysis in the presence of adventitious water and $\mathrm{CsF}$ leads to decarboxylation or transesterification of ent-20 by $t-\mathrm{BuOH}^{26}$ is followed by deprotonation to release isobutylene and $\mathrm{CO}_{2}$ and form ketone 31. Subsequent 5-exo cyclization then affords D-ring-contracted tetracycle 30. We were intrigued to find that the [6-6-5-5] framework of tetracycle $\mathbf{3 0}$ has never been reported. In a control experiment omitting the $\mathrm{CsF}$, we isolated only the noncyclized methyl ketone (31).

Based on the failure of a thermodynamically favored anion to add to the A-ring ketone, it is clear that formation of a tetrahedral intermediate directly adjacent to the existing all-carbon quaternary center must be coupled to a kinetically favored process, such as the observed 5exo cyclization, or to a stronger thermodynamic driving force than enone formation. A 
similar challenge was encountered by $\mathrm{Li}$ and co-workers during an attempt to form the $\mathrm{D}$ ring via aldol condensation. ${ }^{3 e}$ Currently, efforts to rapidly assemble the seven-membered Dring are focused on installation of the $\mathrm{C}-\mathrm{C}$ bond adjacent to this quaternary center prior to the tandem cyclization event. Subsequent ring closure at a remote position is envisioned via several potential annulation strategies.

In summary, we strategically employed solvents bearing homolytically labile $\mathrm{H}$ atoms and a weak stoichiometric $\mathrm{H}$ atom donor to develop tin-free conditions for the tandem cyclization of neutral aminyl radicals. Deuterium labeling experiments were consistent with the solvent as the exclusive $\mathrm{H}$ atom donor to the substrate. Several silanes with BDEs between 86 and 95 proved viable for internal alkyne substrates. We expect these conditions to facilitate cyclization in related systems to access a variety of nitrogen-containing polycyclic scaffolds. Attempted Knoevenagel condensation of an $\mathrm{ABC}$ core bearing a pendant $\beta$-ketoester led to isolation of a novel D-ring-contracted [6-6-5-5] tetracyclic core. Efforts to access a sevenmembered D-ring via several alternative strategies are ongoing and will be reported in due course.

\section{Supplementary Material}

Refer to Web version on PubMed Central for supplementary material.

\section{Acknowledgments}

The authors thank the National Institutes of Health (early efforts in the synthesis were funded by R00-GM097095 and R00-GM097095-S1 to J.L.S. and IMSD Fellowship to A.M.L. R25-GM058905), the National Science Foundation (recent efforts supported by a CAREER Award to J.L.S.: CHE-1554752), and Wayne State University (startup funds to J.L.S., James C. French Scholarship to G.J.R., Rumble-Schaap Fellowship to H.S.S.) for generous financial support. We gratefully acknowledge Christine Arbour (WSU) for technical assistance, the staff of the WSU Lumigen Instrument Center for spectroscopic support, and the NSF for an instrument grant for the $600 \mathrm{MHz}$ NMR used in this work (CHE-0840413).

\section{References}

1. (a) Kobayashi J, Kubota T. Nat Prod Rep. 2009; 26:936-962. [PubMed: 19554242] (b) Chattopadhyay AK, Hanessian S. Chem Rev. 2017; 117:4104-4146. [PubMed: 28205435]

2. Zhang H, Zhang DD, Li JY, Shyaula SL, Li J, Yue JM. RSC Adv. 2016; 6:44402-44409.

3. (a) Coussanes G, Bonjoch J. Org Lett. 2017; 19:878-881. [PubMed: 28181810] (b) Diaba F, Martinez-Laporta A, Coussanes G, Fernández I, Bonjoch J. Tetrahedron. 2015; 71:3642-3651.(c) Ma D, Cheng H, Huang C, Xu L. Tetrahedron Lett. 2015; 56:2492-2495.(d) Guo JJ, Li Y, Cheng B, Xu T, Tao C, Yang X, Zhang D, Yan G, Zhai H. Chem - Asian J. 2015; 10:865-868. [PubMed: 25377776] (e) Xiong X, Li Y, Lu Z, Wan M, Deng J, Wu S, Shao H, Li A. Chem Commun. 2014; 50:5294-5297.(f) Wang L, Xu C, Chen L, Hao X, Wang DZ. Org Lett. 2014; 16:1076-1079. [PubMed: 24506347] (g) Kang B, Jakubec P, Dixon DJ. Nat Prod Rep. 2014; 31:550-562. [PubMed: 24595901]

4. (a) Chen X, Zhang HJ, Yang X, Lv H, Shao X, Tao C, Wang H, Cheng B, Li Y, Guo J, Zhang J, Zhai H. Angew Chem, Int Ed. 2018; 57:947-951.(b) Chen Y, Zhang W, Ren L, Li J, Li A. Angew Chem, Int Ed. 2018; 57:952-956.(c) Shi H, Michaelides IN, Darses B, Jakubec P, Nguyen QNN, Paton RS, Dixon DJ. J Am Chem Soc. 2017; 139:17755-17758. [PubMed: 29120635] (d) Li J, Zhang W, Zhang F, Chen Y, Li A. J Am Chem Soc. 2017; 139:14893-14896. [PubMed: 28956924] (e) Yamada R, Adachi Y, Yokoshima S, Fukuyama T. Angew Chem, Int Ed. 2016; 55:6067-6070.(f) Shvartsbart A, Smith AB III. J Am Chem Soc. 2015; 137:3510-3519. [PubMed: 25756504] (g) Lu Z, Li Y, Deng J, Li A. Nat Chem. 2013; 5:679-684. [PubMed: 23881499] (h) Weiss ME, Kreis LM, 
Lauber A, Carreira EM. Angew Chem, Int Ed. 2011; 50:1-6.(i) Heathcock CH, Hansen MM, Ruggeri RB, Kath JC. J Org Chem. 1992; 57:2544-2553.(j) Heathcock CH, Davidsen SK, Mills S, Sanner MA. J Am Chem Soc. 1986; 108:5650-5651.

5. (a) Ibrahim AA, Golonka AN, Lopez AM, Stockdill JL. Org Lett. 2014; 16:1072-1075. [PubMed: 24506430] (b) Stockdill JL, Lopez AM, Ibrahim AA. Tetrahedron Lett. 2015; 56:3503-3506. [PubMed: 26028785]

6. Kobayashi J, Inaba Y, Shiro M, Yoshida N, Morita H. J Am Chem Soc. 2001; 123:11402-11408. [PubMed: 11707117]

7. (a) Zhang C, Lu X. J Org Chem. 1995; 60:2906-2908.(b) Mercier E, Fonovic B, Henry C, Kwon O, Dudding T. Tetrahedron Lett. 2007; 48:3617-3620.(c) Wallace DJ, Sidda RL, Reamer RA. J Org Chem. 2007; 72:1051-1054. [PubMed: 17253835] (d) Creech GS, Kwon O. Org Lett. 2008; 10:429-432. [PubMed: 18173275]

8. A similar cycloaddition was performed on an earlier intermediate by Zhai and co-workers in ref 4a.

9. (a) Knoevenagel E. Ber Dtsch Chem Ges. 1896; 29:172-174.(b) Tanikaga R, Konya N, Kaji A. Chem Lett. 1985; 14:1583-1586.(c) Dalessandro EV, Collin HP, Guimarães LGL, Valle MS, Pliego JR Jr. J Phys Chem B. 2017; 121:5300-5307. [PubMed: 28471675]

10. Dickson HD, Smith SC, Hinkle KW. Tetrahedron Lett. 2004; 45:5597-5599.

11. See the Supporting Information for details.

12. Temperature refers to the oil bath setting.

13. Zard S. Radical Reactions in Organic Synthesis. Oxford University Press; New York: 2003. 16-94.

14. Luo YR. Handbook of Bond Dissociation Energies in Organic Compounds. CRC Press; New York: 2003. 1-367.

15. For photolytic reactions of aminyl radicals from $\mathrm{N}-\mathrm{Cl}$ bonds, see leading reference:Stella $\mathrm{L}$. Angew Chem, Int Ed Engl. 1983; 22:337-422.

16. (a) Senboku H, Hasegawa H, Orito K, Tokuda M. Tetrahedron Lett. 2000; 41:5699-5703.(b) Hasegawa H, Senboku H, Kajizuka Y, Orito K, Tokuda M. Tetrahedron. 2003; 59:827-832.(c) Banwell MG, Lupton DW. Heterocycles. 2006; 68:71-92.(d) Schwartz BD, Jones MT, Banwell MG, Cade IA. Org Lett. 2010; 12:5210-5213. [PubMed: 20977260] (e) White LV, Schwartz BD, Banwell MG, Willis AC. J Org Chem. 2011; 76:6250-6257. [PubMed: 21644519]

17. The chloromethylated tricycle was observed by MS of a sample allowed to stand in dichloromethane over a period of several days.

18. Similar reactivity was observed in:Bowman WR, Clark DN, Marmon RJ. Tetrahedron. 1994; 50:1295-1310.

19. For example, on $422 \mathrm{mg}$ scale, the yield was $11 \%$.

20. Robertson J, Pillai J, Lush RK. Chem Soc Rev. 2001; 30:94-103.

21. The possible 1,5-HAT reaction is outlined below for clarity.

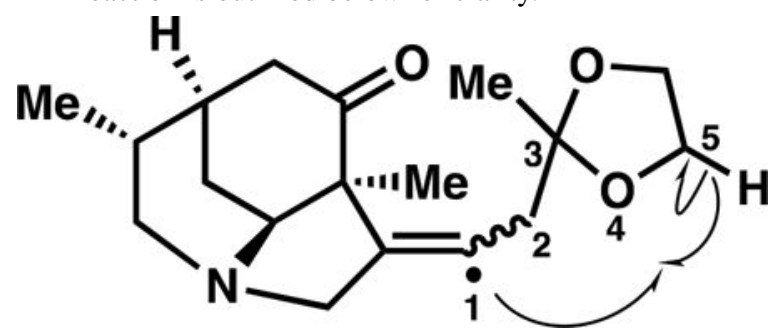

22. Jensen T, Pedersen H, Bang-Andersen B, Madsen R, Jørgensen M. Angew Chem, Int Ed. 2008; 47:888-890.

23. Efforts to purify intermediates led to decomposition.

24. Holmquist CR, Roskamp EJ. J Org Chem. 1989; 54:3258-3260.

25. (a) Rand L, Swisher JV, Cronin CJ. J Org Chem. 1962; 27:3505-3507.(b) Prout FS, Abdel-Latif AA, Kamal MR. J Chem Eng Data. 1963; 8:597-599.(c) Rand L, Haidukewych D, Dolinski RJ. J Org Chem. 1966; 31:1272-1274.(d) Lelean PM, Morris JA. Chem Commun. 1968; 5:239.(e) Clark JH. Chem Rev. 1980; 80:429-452.(f) Arai H, Ohno A, Tani Y-i, Imachi S, Mukaiyama T. Chem 
Lett. 2002; 31:92-93.(g) Khan KM, Muhammad MT, Khan I, Perveen S, Voelter W. Monatsh Chem. 2015; 146:1587-1590.

26. A mass consistent with formation of the tert-butyl ester is observed by mass spectroscopy during the reaction. 


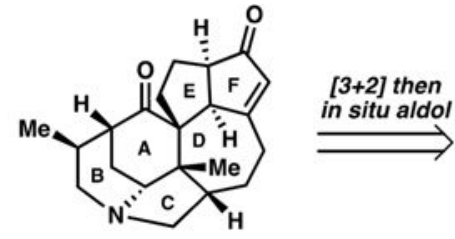

daphniyunnine $C(1)$
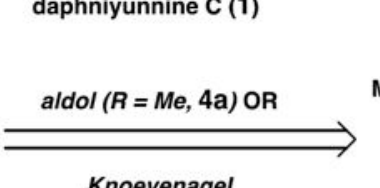

Knoevenagel

( $\left.\mathrm{R}=\mathrm{CH}_{2} \mathrm{CO}_{2} \mathrm{Et}, 4 \mathrm{~b}\right)$

condensation

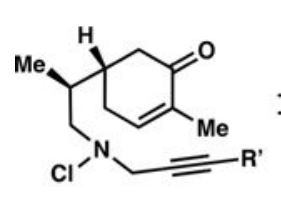

5

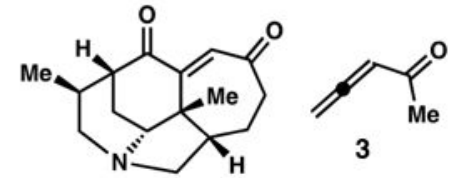

2

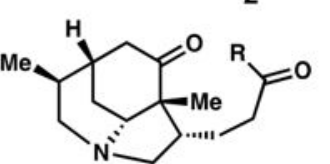

4

tandem $\mathrm{N}$-centered radical cyclization

then then
hydrogenation

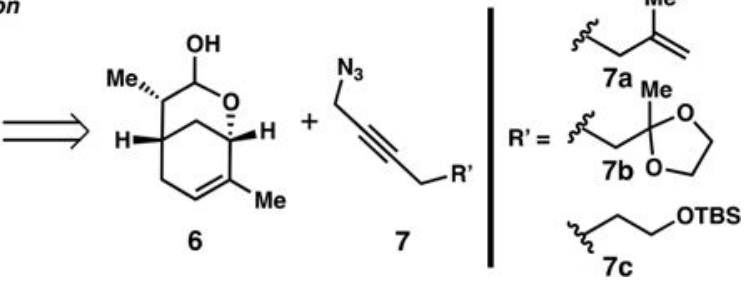

Scheme 1.

Retrosynthetic Analysis of Daphniyunnine C 

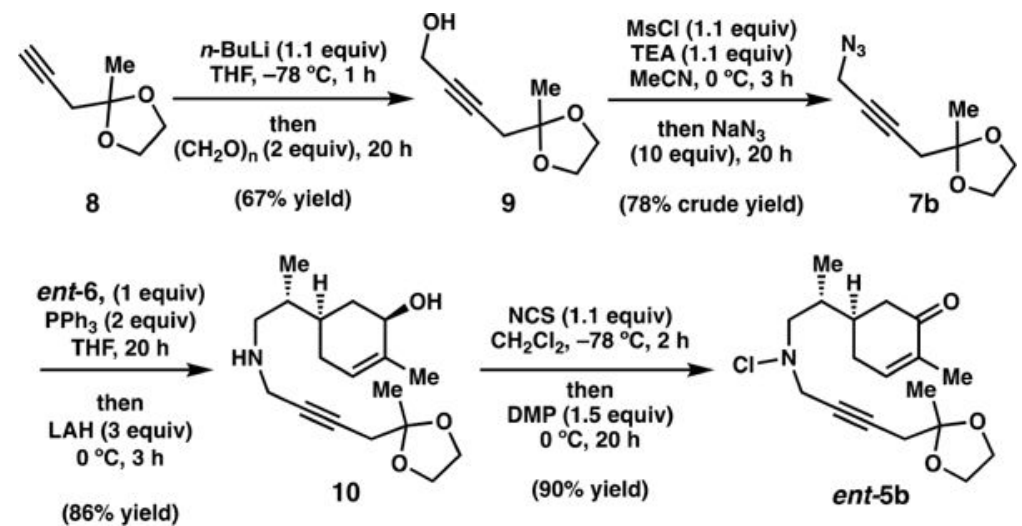

Scheme 2.

Synthesis of Ketal-Appended Cyclization Substrate via aza-Wittig/in situ LAH Reduction 


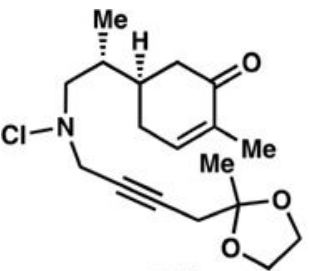

ent-5b

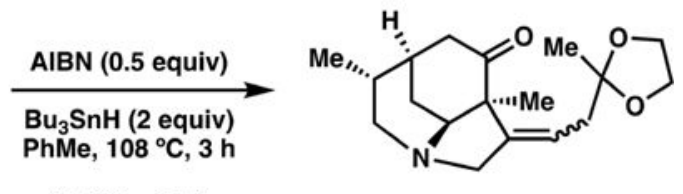

$(0-48 \%$ yield $)$

11

Scheme 3.

Inconsistent Tandem Cyclization with $\mathrm{Bu}_{3} \mathrm{SnH} / \mathrm{PhMe}$ 

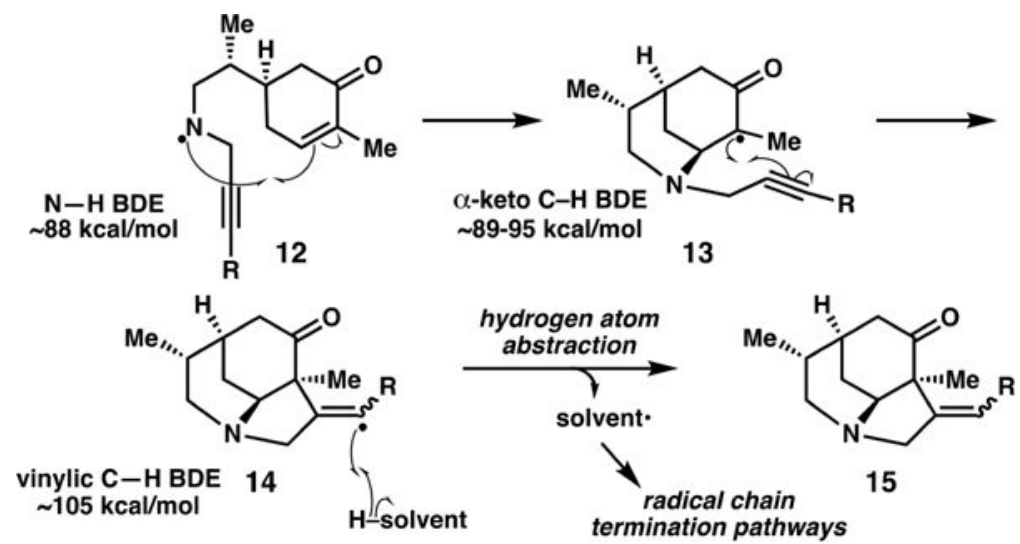

Scheme 4.

Mechanism and Approximate Relevant BDEs for the Tandem Cyclization 

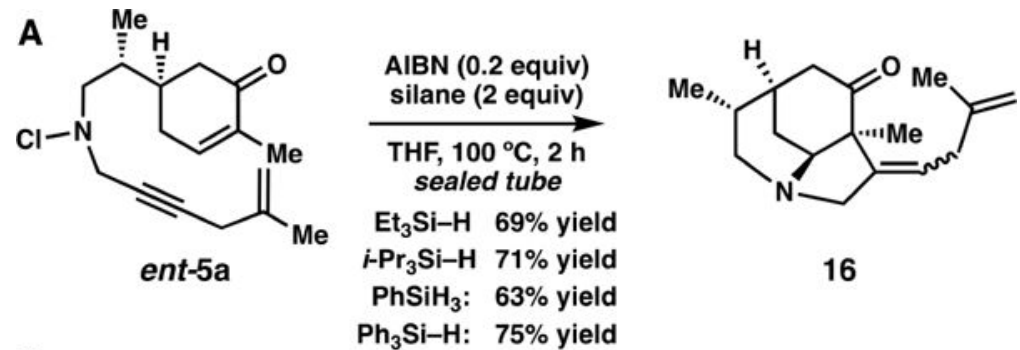

16

B<smiles>C#CCN(Cl)C[C@H](C)[C@H]1CC=C(C)C(=O)C1</smiles>

17

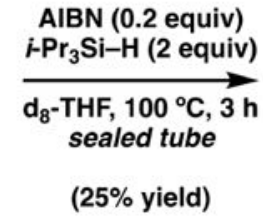

(25\% yield)

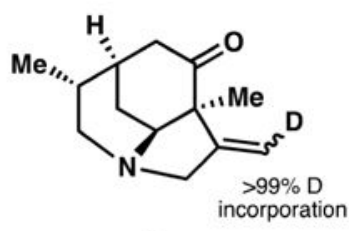

18

Scheme 5.

(A) Efficient Cyclization of Methallyl Substrate in the Presence of Various Silanes and (B) Incorporation of D Using $d_{\delta} \mathrm{THF}$ 

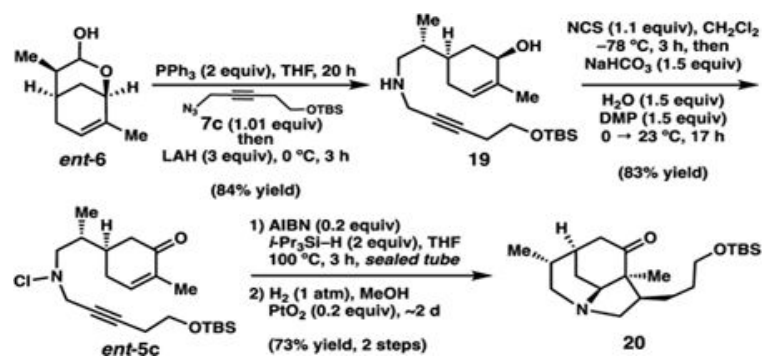

Scheme 6 .

Synthesis of ABC Core for Knoevenagel Approach 


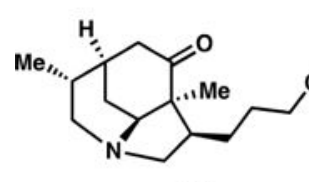

20
1) $\mathrm{Et}_{2} \mathrm{O}, \mathrm{HCl}, 5 \mathrm{~min}$

2) TFA (1 equiv), $\mathrm{CHCl}_{3}$

$15 \mathrm{~min}$, then

DMP ( 2 equiv), $60^{\circ} \mathrm{C}, 2 \mathrm{~h}$

3) $\mathrm{SnCl}_{2}$ (2 equiv), $\mathrm{CHCl}_{3}$

ethyl diazoacetate (7 equiv)

$60{ }^{\circ} \mathrm{C}, 15 \mathrm{~min}$

( $54 \%$ yield, 3 steps)

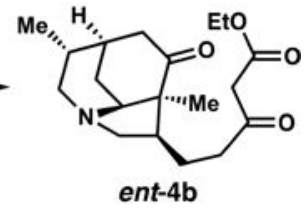

Scheme 7.

Roskamp Coupling Affords Knoevenagel Precursor 

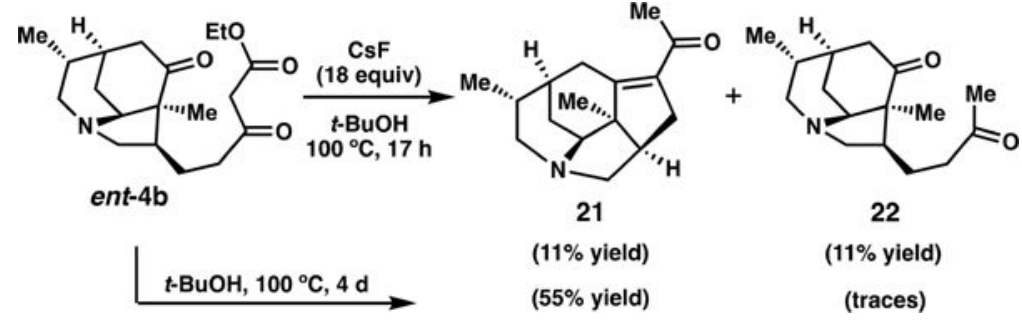

t-BuOH, $100^{\circ} \mathrm{C}, 4 \mathrm{~d}$

(55\% yield)

(11\% yield)

(traces)

Scheme 8.

Attempted Knoevenagel Cyclization Yields Undesired Ring-Contracted Product 